
reading

Alexandra Witze savours seven books saluting the 50th anniversary of the lunar touchdown.

Buzz Aldrin steps off the Lunar Module to become the second person on the Moon on 20 July 1969

$\mathrm{I}$ n May 1961, US President John F. Kennedy delivered an astonishing call to action. "We choose to go to the Moon," he declared, because it would "measure the best of our energies and skills". Kennedy wasn't, however, all that interested in space. He said as much to then-NASA administrator James Webb in November 1962, 18 months after committing the United States to landing a person on the Moon by the decade's end. In the depths of the cold war, geopolitical concerns were the biggest factor in NASA's Apollo project (see page 167).

The Soviet Union's space achievements - including the 1957 launch of Sputnik, the first satellite, and Yuri Gagarin's pioneering Earth orbit in 1961 - constituted a formidable challenge. And, as presidential historian Douglas Brinkley outlines in his new book American Moonshot, Kennedy mustered all his political will to ensure that the United States would lead in space. By the time Neil Armstrong stepped onto the surface of the Moon on 20 July 1969, the space race was over. Fifty years on, the only humans who have ever travelled beyond low Earth orbit are the 24 Americans who flew to the Moon and back - including 12 who walked on its surface.

The story of who they are, and how they got there, has been told by scores of writers, such as Andrew Chaikin in his authoritative 1994 book A Man on the Moon. Now, to commemorate the half-century of Armstrong's one small step, a fresh crop of books attempts to bring new insight into the Apollo project - along with what led to it, and from it.

\section{APOLLO IN CONTEXT}

For a one-stop overview of how Apollo unfolded, One Giant Leap by journalist Charles Fishman wins. It lays out the basics of how NASA designed and built the unprecedented hardware required to go to the Moon, from the mighty Saturn V rocket to the improbably spindly lunar lander. Fishman sets his narrative in the social context of the 1960s, highlighting US fears about Soviet military dominance and the concurrent rise of the civil-rights movement. It shows how Apollo sprang up at a time of international and domestic tumult.
There are delightfully nerdy chapters, such as one on the development of Apollo's computer hardware and software. Fishman describes the work of engineer Charles Stark 'Doc' Draper's legendary team at the Massachusetts Institute of Technology (MIT) in Cambridge. This crucial group developed the navigation and guidance systems that enabled the Apollo $11 \mathrm{crew}$ to reach their target, undock the lunar lander and pilot it to a precise site on the basalt plain known as the Sea of Tranquillity (Mare Tranquillitatis). Fishman also lauds the work of Bill Tindall. The NASA manager and engineer knew how to translate MIT's breakthroughs into a successful mission - deleting extraneous computer code and ensuring that only the most reliable and well-tested commands remained.

\section{ROCKET BOOSTERS}

Inevitably, several other books celebrate the engineers behind the feat. Nancy Atkinson's Eight Years to the Moon features Earle Kyle, one of the few African American aerospace engineers of the time, 
American Moonshot: John F. Kennedy and the Great Space Race

DOUGLAS BRINKLEY

Harper (2019)

One Giant Leap: The Impossible Mission that Flew Us to the Moon

CHARLES FISHMAN

Simon \& Schuster (2019)

Eight Years to the Moon: The History of the Apollo Missions

NANCY ATKINSON

Page Street (2019)

The Apollo Chronicles: Engineering

America's First Moon Missions

BRANDON R. BROWN

Oxford University Press (2019)

Apollo's Legacy: Perspectives on the Moon

Landings

ROGER D. LAUNIUS

Smithsonian Books (2019)

Moon Rush: The New Space Race

LEONARD DAVID

National Geographic (2019)

The Moon: A History for the Future

OLIVER MORTON

The Economist Books (2019)

and Dottie Lee, who not only calculated spacecraft trajectories but also designed and tested the vehicles. A more personal view comes in The Apollo Chronicles by Brandon Brown, a physicist whose father worked on the project. Brown takes us leap by leap through the 1960s, tracing the parallel engineering work at Cape Canaveral (the launch site in Florida), the Manned Spacecraft Center in Houston, Texas (now the Johnson Space Center), and the rocketry group in Huntsville, Alabama, led by German-born Wernher von Braun.

Brown peppers his account with on-theground details of how engineers dealt with unexpected problems. Some were simple. In Houston, technicians working to perfect Apollo's control thrusters panicked on finding a mysterious residue coating vehicles in the car park. Could explosives leak that far from the laboratory? A chemist subsequently identified the substance as goldenrod pollen. Other issues were complex. Revisiting the tragic Apollo 1 fire of 1967, in which astronauts Gus Grissom, Edward White and Roger Chaffee died during a capsule test at the Cape, the horror of engineers familiar with the electrical systems that killed them is palpable.

\section{SOCIAL JUSTICE}

The Apollo project involved some 400,000 people working for a decade to send a dozen humans to the surface of the Moon. For a holistic analysis, there's no better source than Roger Launius, former chief historian for NASA. In Apollo's Legacy, Launius explores the many ways in which the public has interpreted the landings - from denial to embracing the whole-Earth view

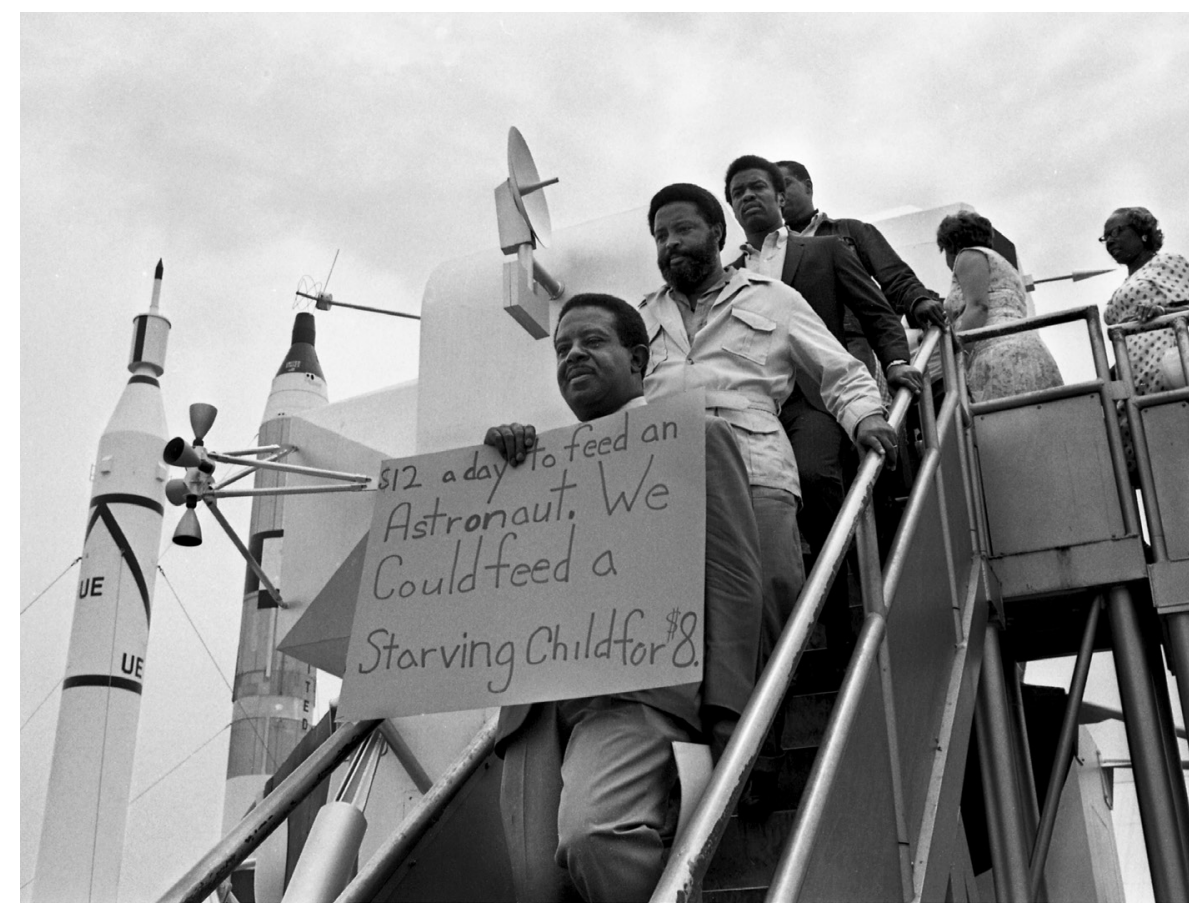

Civil-rights leaders including Ralph Abernathy (front) protest at the launch of the Apollo 11 mission.

from space (see go.nature.com/2ne4zai). He reminds us that the Apollo project, although often lauded as a visionary achievement, was not well accepted by many in the United States - including scientists - at the time. A 1967 poll found that residents in six US cities saw tackling pollution and poverty, for instance, as more important.

Launius highlights the tensions between space policy and social policy. On the eve of the Apollo 11 launch, civil-rights leader Ralph Abernathy took several hundred people to Cape Canaveral to demonstrate against the massive spending on the space programme in the face of poverty and social injustice. "We do not oppose the Moonshot," said Hosea Williams, a leader of the group. "Our purpose is to

"The Apollo project, although often lauded as a visionary achievement, was not well accepted by many in the United States.' protest America's inability to choose human priorities." Politics, science and engineering working in concert, Launius notes, might have been able to send a man to the Moon, but back on Earth, solutions to egregious social issues such as racism and inequity were and are slow in coming. Many people continue to hold up Apollo as an example of how the Moonshot approach might solve some of the most pressing problems facing society, such as climate change. History shows this analogy is far from perfect.

Today, following in the steps of former presidents George H. W. and George W. Bush, Donald Trump - certainly no Kennedy - has tasked NASA with returning astronauts to the lunar surface by 2024. But the landscape now is wildly different, as journalist Leonard David describes in Moon Rush. Commercial companies such as SpaceX and Blue Origin are entering the realm of space flight, and China is a strong contender for sending the next human to the Moon.

Whoever takes that step, Oliver Morton, an editor at The Economist, dubs it the Return. The Moon, his paean to our satellite, gives the scientific, historical and cultural context to this pressing possibility. This is a book to bend your mind with the mysteries of the swirl-like markings on the lunar surface or the cadence of impacts that have bombarded the inner Solar System. It links the geological history of Earth with the chances of asteroid impacts ferrying life between planets. And it tosses in an apocalyptic scene of the Moon's birth, from a cosmic collision involving Earth. Morton, a former editor at Nature (and my former manager), has written what is surely the most eloquent exploration of our modern understanding of the Moon.

Yet we should not be seduced by the nostalgia of Apollo or the allure of the Return as we grapple with vast, multipronged challenges on Earth. Then-NASA administrator Thomas Paine recognized as much at the Apollo 11 launch, when he spoke to Abernathy. Paine later recalled admitting that compared with solving poverty, racism and other injustices, the "great technological advances of NASA were child's play". - 